\title{
Accuracy of transverse cerebellar diameter by ultrasonography in the evaluation gestational age of fetus
}

\author{
V Natraj Prasad, Vivek Dhakal, Pramod Kumar Chhetri \\ Department of Radiodiagnosis, College of Medical Sciences- Teaching Hospital, Bharatpur, Nepal
}

\section{Correspondence \\ Dr. Vivek Dhakal \\ Department of Radiodiagnosis, \\ College of Medical Sciences- \\ Teaching Hospital, Bharatpur, Nepal \\ Email: \\ dr.vivek.dhakal@gmail.com}

DOI: http://dx.doi.org/10.3126/ jemsn.v13i1.16660

Article received: Nov $5^{\text {th }} 2016$ Article accepted: J an $22^{\text {nd }} 2016$

\begin{abstract}
Background \& Objectives: Estimation of the length of gestation is of paramount importance to obstetricians. The fetal cerebellum grows progressively along gestational period and transverse cerebellar diameter can be used as a new biometric parameter to assess the gestational age of fetus. This study was done to evaluate the accuracy transverse cerebellar diameter against other regularly measured parameters like biparietal diameter, head circumference, abdominal circumference and femur length in pregnant women between 15 to 40 weeks of gestation. Materials \& Methods: In this study of 60 pregnant women between 15-40 weeks of gestation, all the parameters like biparietal diameter, head circumference, abdominal circumference, femur length and transverse cerebellar diameter were measured with ultrasonography. The measured values were then correlated with gestational age using regression coefficient. Results: Gestational age estimated by transverse cerebellar diameter $(\mathrm{R} 2=0.989 ; \mathrm{p}<0.001)$ had good predictive value which was comparable to gestational age estimated by biparietal diameter (R2 $=0.929 ; \mathrm{P}<0.01)$, head circumference $\left(\mathrm{R}^{2}=0.964 ; \mathrm{P}<0.01\right)$, abdominal circumference $\left(\mathrm{R}^{2}=0.931 ; \mathrm{P}<0.01\right)$ and fetal length $\left(\mathrm{R}^{2}=0.966 ; \mathrm{P}<\right.$ 0.01). Conclusion: Transverse cerebellar diameter has a good predictive accuracy for gestational age estimation which is comparableto other routinely used parameters and can be used as an alternative parameter to predict the gestational age.
\end{abstract}

Key words: Gestational age; transver se cer ebellar diameter.

Citation: Prasad VN, Dhakal V, Chhetri PK. Accuracy of transverse cerebellar diameter by ultrasonography in the evaluation gestational age of fetus. JCMS Nepal. 2017;13(1):225-8.

\section{INTRODUCTION}

Estimation of the length of gestation has a critical role in clinical practice to ensure appropriate management of newborn. It is important to distinguish pre-term from term infants' because low birth weight either due to short gestation or due to being light for date has profound implication in obstetric and neonatal practice. ${ }^{1}$ Among the various parameters, last menstrual period (LMP) is the most accurate method of estimating the gestational age of the fetus only if the mother is sure of the exact date. ${ }^{2}$ Estimated date of delivery calculated from only the menstrual gestational age (GA) may not be reliable. It may lead to unnecessary induction, dysfunctional labour and caesarean section which have profound implication in neonatal and maternal morbidity. ${ }^{3}$ Ultrasonography (USG) helps in evaluating the duration of pregnancy based on measurement of the fetus, using size as an indirect indicator of menstrual age. Currently the various parameters which are being used include the biparietal diameter (BPD), abdominal circumference (AC), head circumference (HC) and femur length (FL) ${ }^{4-6}$ But during third trimester when there is excessive moulding of the head, BPD and HC become unreliable, in which case trans-cerebellar diameter (TCD) becomes a reliable marker for estimation of gestational age since the cerebellum is not liable to change in its form and size as it is protected very well inside the posterior fossa surrounded by dense petrous and occipital bones. ${ }^{7}$

TCD has emerged as a useful parameter for assessing fetal growth retardation. The purpose of the current study is to evaluate the accuracy of transverse cerebellar diameter against the conventional parameters in assessing gestational age 
in normal pregnant mothers between 15 to 40 weeks.

\section{MATERIALS AND METHODS}

This study was undertaken on 60 consecutive patients referred for ultrasonography in Department of Radiology, College of Medical Sciences Teaching Hospital from January to December 2015. The measurements were obtained with the patient supine with a curvilinear array real time, B-mode ultrasound, equipped with a $3.5 \mathrm{MHz}$ transducer (Samsung Medison Accuvix A30 machine). Each of the parameters was focused according to specific imaging criteria, calliper placement, and averaging of at least two measurements for each were followed.

In each patient, BPD, HC, AC, FL and TCD were measured. Transverse views of the fetal transcerebellar diameter were obtained as shown in figure 1. Measurements were obtained by placing the callipers at the maximum cerebellar diameter (greatest outer-to-outer margins of the cerebellum). All the pregnant patients who were uncertain of their LMP or irregular LMP were excluded from the study. High risk pregnancies with previous history of IUGR, hypertension, pre-eclampsia, diabetes, etc were also excluded. To decrease the inter-observer variability, a single radiologist performed the measurements. To decrease the intraobserver variability the average value of two measurements was used. Regression analysis was done to compare each USG measured parameter i.e. $\mathrm{TCD}, \mathrm{BPD}, \mathrm{HC}, \mathrm{AC}$ and $\mathrm{FL}$ with the gestational age of fetus. Correlation coefficients were also used to compare TCD with BPD, HC, AC and FL.

\section{RESULTS}

Sixty (60) healthy pregnant women underwent routine USG examinations, and the measurements were obtained. Age distribution of pregnant ladies was between 18 to $35 \mathrm{yrs}$. Most of the pregnancies were below 27 wks of gestation (41.7\%). A total of $38.3 \%$ of pregnancies were between 33 to 40 wks and $20 \%$ of the pregnancies were between 27 to 32 wks.Most of the patients were primigravidae (50\%), $40 \%$ were gravida- 2 and gravida-3 \& 4 were $5 \%$ each.

Regression analysis was used to find a correlation between the various parameters like BPD, HC, AC, FL and TCD with last menstrual gestational age.r (Regression coefficient), $\mathrm{R}^{2}$ (coefficient of determination) and $\mathrm{p}$ values were calculated. (Table 1)
This study showed good correlation between the gestational age of fetus with respective parameters like BPD, HC, AC, FL and TCD. TCD showed good correlation $\left(\mathrm{R}^{2}=0.989 ; \mathrm{p}<0.001\right)$ with gestational age which was comparable to other parameters routinely used for estimation of gestational age. $\mathrm{BPD}\left(\mathrm{R}^{2}=0.964 ; \mathrm{p}<0.001\right), \mathrm{HC}$ $\left(\mathrm{R}^{2}=0.982 ; \mathrm{p}<0.001\right), \mathrm{AC}\left(\mathrm{R}^{2}=0.965 ; \mathrm{p}<\right.$ $0.001)$, FL $\left(\mathrm{R}^{2}=0.983 ; \mathrm{p}<0.001\right)$.

There was also good predictive accuracy of TCD with various other parameters. $\operatorname{BPD}\left(\mathrm{R}^{2}=0.889\right.$; $\mathrm{p}<0.001), \mathrm{HC}\left(\mathrm{R}^{2}=0.937 ; \mathrm{p}<0.001\right), \quad \mathrm{AC}\left(\mathrm{R}^{2}=0.881\right.$; $\mathrm{p}<0.001)$ and $\mathrm{FL}\left(\mathrm{R}^{2}=0.929 ; \mathrm{p}<0.001\right)$.

By using the USG derived data, scatter plots (Figure 2) and regression equations (Table 2) for TCD were devised.

\section{DISCUSSION}

Estimation of length of gestation is of paramount importance to obstetricians with regard to method of termination of pregnancy, elective induction of labor, elective caesarian section, management of high risk pregnancies and evaluation of intrauterine growth restriction (IUGR). In this study it was noted that early sonographic visualization of the cerebellum occurred as early as 14 weeks. On USG the characteristic image of cerebellum appears as two lobes on either side of midline in the posterior cranial fossa with a characteristic butterfly-like appearance. The sonographic evaluation of cerebellar growth reveals a linear relationship with GA during the second trimester, the measurements in millimeters being approximately equal to the gestational age in weeks. However, later in the gestation the curve of the cerebellar growth tends to flatten out, as is often seen in human biology.

Guan $\mathrm{B}^{8}$ found curvilinear relationship between TCD and gestational age $(\mathrm{R} 2=0.99624, \mathrm{P}<$ $0.0005)$. He concluded that the function of the TCD in the evaluation of fetal growth and development is better than any other parameter. In a similar study by Adeyekun $\mathrm{AA}^{9}$, the TCD range was 11.9-59.7 $\mathrm{mm}$ (mean $=34.2 \mathrm{~mm}$ ). He found that TCD correlated more significantly with menstrual age compared with other biometric parameters in Nigerian population. $(\mathrm{r}=0.984, \mathrm{p}=0.000)$. TCD had a higher predictive accuracy of $96.9 \% \pm 12$ days), BPD (93.8\% \pm 14.1 days) and $\mathrm{AC}(92.7 \% \pm$ 15.3 days)

Similarly in this study the range of values of TCD was 14 to 50 (mean $=32.2)$. Good curvilinear correlation was obtained between TCD and gestational age. $(\mathrm{R} 2=0.989, \mathrm{P}<0.001)$. Comparing 
Table 1: Correlation of GA with BPD, HC, AC, FL and TCD

$\begin{array}{lllll}\text { Parameters compared } & \mathrm{r} & \mathrm{R}^{2} & \mathrm{P} \text { value } & \text { Std. Error(+/-) } \\ \text { GA vs BPD } & 0.964 & 0.929 & <0.001 & 2 \mathrm{wk} \\ \text { GA vs HC } & 0.982 & 0.964 & <0.001 & 1.4 \mathrm{wk} \\ \text { GA vs AC } & 0.965 & 0.931 & <0.001 & 1.9 \mathrm{wk} \\ \text { GA vs FL } & 0.983 & 0.966 & <0.001 & 1.4 \mathrm{wk} \\ \text { GA vs TCD } & 0.989 & 0.978 & <0.001 & 1.1 \mathrm{wk}\end{array}$

Table 2: Relationship of GA with various parameters

Equation showing relationship of GA with respective parameters

$\mathrm{GA}=14.02+0.020 \times(\mathrm{BPD})+0.00297 \times(\mathrm{BPD})^{2}$

$\mathrm{GA}=15.46-0.023 \times(\mathrm{HC})+0.000274 \times(\mathrm{HC})^{2}$

$\mathrm{GA}=9.22+0.064 \times(\mathrm{AC})-0.0000669 \times(\mathrm{AC})^{2}$

$\mathrm{GA}=9.83+0.27 \times(\mathrm{FL})+0.00151 \times(\mathrm{FL})^{2}$

$\mathrm{GA}=2.21+0.95 \times(\mathrm{TCD})-0.00404 \times(\mathrm{TCD})^{2}$

with other parameters like $\mathrm{BPD}(\mathrm{R} 2=0.929, \mathrm{P}$ $<0.001)$, $\mathrm{HC}(\mathrm{R} 2=0.964, \mathrm{P}<0.001), \mathrm{AC}(\mathrm{R} 2=$ $0.931, \mathrm{P}<0.001)$ and FL $(\mathrm{R} 2=0.966, \mathrm{P}<0.001)$, TCD showed the good correlation comparable to other parameters suggesting that TCD may be the used as an alternative tool for the evaluation of gestational age of fetus when the LMP is unknown. Mcleary et al. ${ }^{10}$ studied the measurement of transcerebellar diametr with USG in 225 normal fetuses ranging from 15 to 39 weeks of gestational age and found it to closely correlate with BPD. The cerebellum is well protected by the dense petrous and occipital bones thus well protected by the extrinsic deforming forces unlike BPD. They proposed that the trans-cerebellar diameter may be useful in estimating fetal agewhere extrinsic pressure has deformed the skull and led to decreased biparietal diameter.

Similarly in this study there was good correlation between the BPD and TCD $(\mathrm{R} 2=0.929, \mathrm{P}$ value $<$ $0.001)$. Therefore, TCD may be preferred over BPD in assessing gestational age of fetuses in circumstances where head is deformed for eg. as in moulding or dolicocephaly.

\section{CONCLUSION}

There is good correlation between TCD and other parameters in normal pregnancies at 15 to 40 weeks of gestation.TCD may be used as an alternative

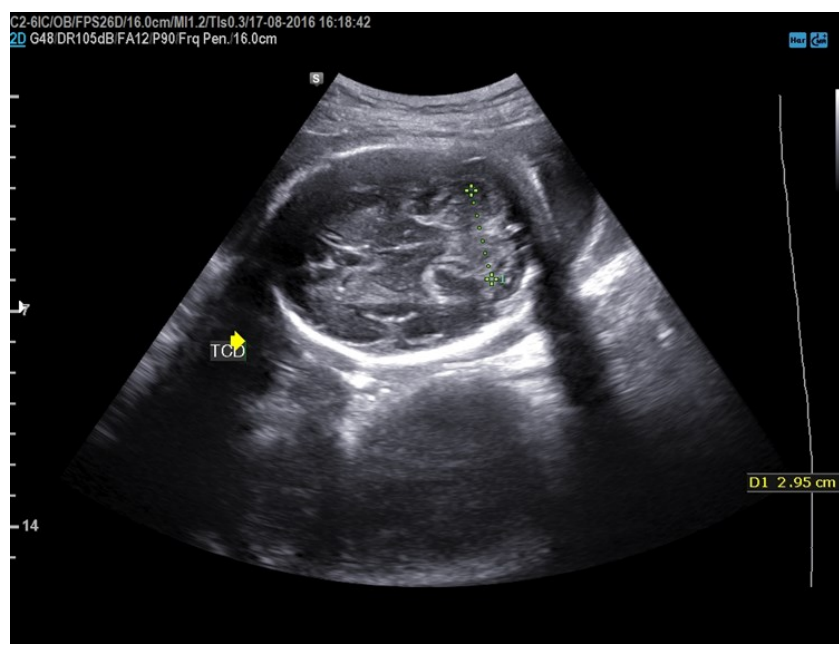

Figure 1: Ultrasonic measurement of fetal transcerebellar diameter

GA-LMP(wk) Vs TCD(mm)

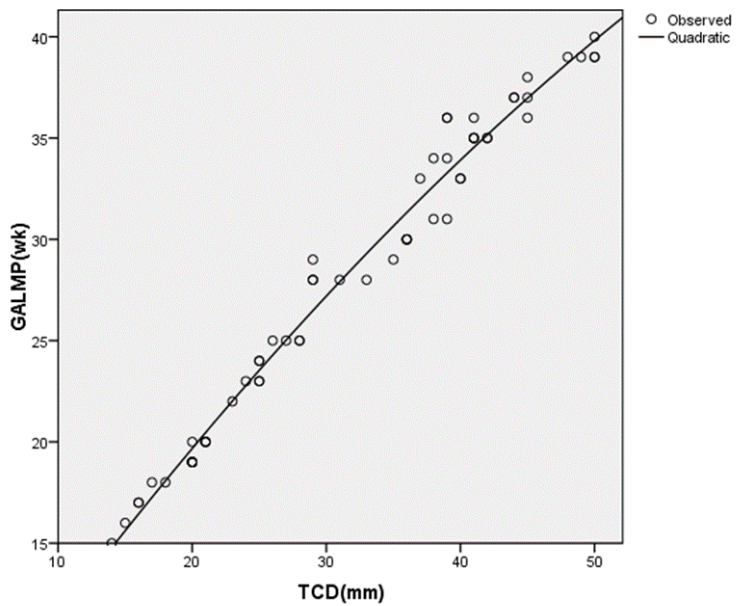

Figure 2: Scatter plot of the trans-cerebellar diameter (measured in millimetres) against gestational age (in weeks) demonstrates a curvilinear graph. The growth pattern can be described by a second-order polynomial equation.

parameter for gestational age assessment along with BPD, HC, AC and FL. TCD measurements are not affected by conditions which affect BPD for eg. 
moulding and dolicocephaly. FL measurements can be faulty due to inclusion of unossified epiphyses. Such problems are not encountered during TCD measurement.

\section{REFERENCES}

1. Feresu SA, Gillespie BW, Sowers MF, Johnson TR, Welch $\mathrm{K}$, Harlow SD. Improving the assessment of gestational age in a Zimbabwean population. Int $\mathrm{J}$ Gynaecol Obstet. 2002;78(1):7-18. DOI: 10.1016/S0020-7292(02)00094-2.

2. Cunningham F, Leveno KJ, Bloom SL, Hauth JC, Gilstrap L, Wenstrom KD. Williams obstetrics. 22nd ed. New York: McGraw-Hill, Medical Pub. Division; 2005.

3. Benson CB, Doubilet PM. Fetal measurements: normal and abnormal fetal growth. In: Rumack CM, Wilson SR, Charboneau JW, Levine D, editors. Diagnostic ultrasound. 4th ed. Philadelphia, PA: Elsevier Mosby Inc.; 2011. p. 1455-71.

4. Hohler CW. Ultrasound estimation of gestational age. ClinObstet Gynecol. 1984;27(2):314-26. DOI: 10.1097/00003081-198406000-00007.

5. Hadlock FP, Harrist RB, Sharman RS, Deter RL, Park SK. Estimation of fetal weight with the use of head, body, and femur measurements--a prospective study. Am J Obstet Gynecol. 1985;151(3):333-7. DOI: 10.1016/0002-9378(85) 90298-4.

6. Hadlock FP, Deter RL, Harrist RB, Park SK. Estimating fetal age: computer-assisted analysis of multiple fetal growth parameters. Radiology. 1984;152(2):497-501. DOI: 10.1148/radiology.152.2.6739822. PMID:6739822.

7. Mikovic Z, Markovic A, Dukic M, Pazin V. Growth of the fetal cerebellum in normal pregnancy. JugoslGinekolPerinatol. $\quad 1989 ; 29(5-6): 157-60$. PMID:2701110.

8. Guan B. Surveillance of fetal growth and fetal cerebellar transverse diameter by ultrasonographic measurement. Zhonghua Yi XueZaZhi. 1992;72(2):65-7, 126.

9. Adeyekun AA, Orji MO. Predictive accuracy of transcerebellar diameter in comparison with other fetal biometric parameters for gestational age estimation among pregnant Nigerian women. East Afr Med J. 2014;91(4):138 -44. PMID:26859033.

10. Mcleary R, Kuhns L, Barr M. Ultrasonography of the fetal cerebellum. Radiology. 1984;151:439-42. DOI: 10.1148/ radiology.151.2.6709916. PMID:6709916. 